\title{
PERANCANGAN APLIKASI PATROLI KEAMANAN DAN KESELAMATAN KAMPUS
}

\author{
Arief Rahman ${ }^{1)}$, Muhammad Hanif Ramdhani' ${ }^{2)}$, Sri Gunani Partiwi ${ }^{3)}$, Anny Maryani ${ }^{4)}$ \\ ${ }^{1,2,3,4)}$ Departemen Teknik Industri, Fakultas Teknologi Industri, Institut Teknologi Sepuluh Nopember
}

\begin{abstract}
Abstrak . Keamanan lingkungan merupakan kondisi utama untuk menciptakan suasana kerja yang kondusif dan sebagai upaya untuk menjaga segala aset atau sumber daya dalam suatu organisasi. Semakin tinggi tingkat keamanan suatu lingkungan akan semakin rendah risiko kerugian akibat kehilangan aset atau bahaya yang mengancam personil. Petugas kemanan dalam suatu lingkungan kerja menjadi salah satu tumpuan untuk melaksanakan fungsi-fungsi pengamanan dan penyelamatan. Proses monitoring keamanan lingkungan kampus dilakukan secara rutin dengan jadwal patroli yang terjadwal dan umumnya memiliki klasterisasi area pengamanan agar optimal. SIGAP ITS merupakan aplikasi bergerak yang dirancang untuk memastikan personil yang bertugas mengikuti jadwal optimal patroli dan memastikan personil telah mengunjungi gedung yang harus diawasi. Imlementasi SIGAP ITS menjadi solusi pemantauan sistem keamanan yang realtime dan dinamis. Evaluasi terhadap kemudahan dan efektivitas antar muka aplikasi bergerak telah dilakukan menggunakan System Usability Scale dengan tingkat usabilitas mencapai 91.4\%..
\end{abstract}

Kata Kunci: Sistem Patroli, Aplikasi Bergerak, Keamanan Dan Keselamatan

Institut Teknologi Sepuluh Nopember (ITS) Surabaya mengelola banyak aset bernilai tinggi dalam area kampus yang sangat luas. Jumlah civitas academica ITS juga tergolong cukup besar yaitu lebih dari 20000 mahasiswa dan lebih dari 2000 pegawai [1]. Pengelolaan keamanan dan keselamatan kampus menjadi kewajiban bagi ITS untuk mengantisipasi adanya kemungkinan gangguan seperti pencurian, pencopetan, begal, dan bentuk kejahatan lainnya. Jumlah kerugian akibat pencurian atau kehilangan selama tahun 20142016 masih terjadi didalam kampus ITS dan menunjukkan pentingnya peningkatan pengamanan dan perbaikan pengelolaan sistem keamanan.
Salah satu alternatif upaya optimalisasi beban kerja personil keamanan dan keselamatan kampus adalah peningkatan peran patroli kampus yang lebih efektif [2]. Elmadhania telah melakukan analisa klasterisasi area patroli kampus ITS dengan menggunakan pendekatan Vehicle Routing Problem untuk memastikan semua gedung dapat dikunjungi oleh petugas patroli. Rekomendasi yang diberikan berupa pembagian cluster wilayah kerja ke dalam 5 (lima) pos keamanan, penjadwalan dan rute patroli, alokasi jumlah petugas di setiap shift, serta usulan tambahan penugasan patroli pengawasan pengguna jalan untuk optimalisasi beban kerja petugas. Gambar 1 menampilkan area dan rute patroli yang telah direkomendasikan. 


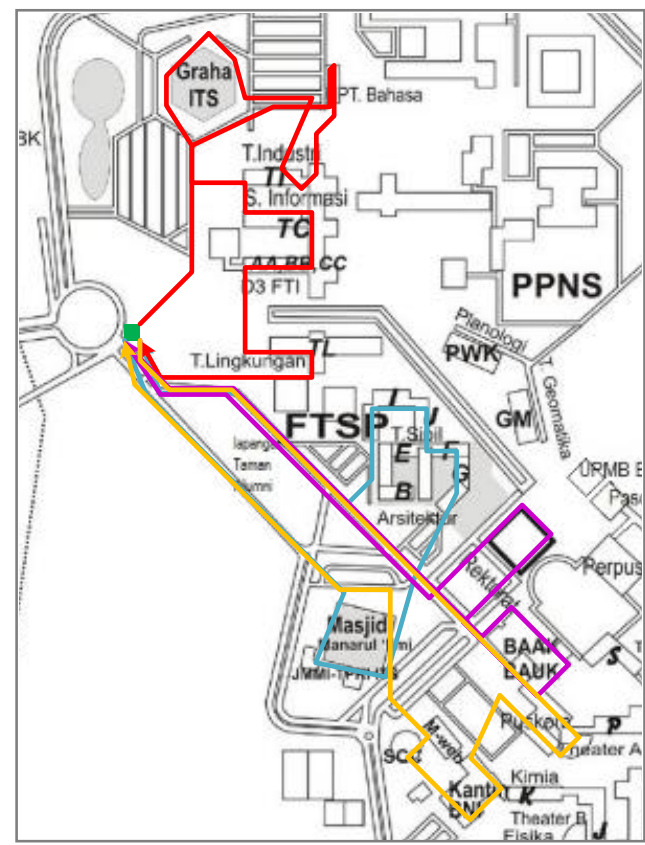

Gambar. 1 Rancangan Rute Patroli Kampus ITS Sukolilo Sumber: (Elmadhania, 2017)
Satuan keamanan dan keselamatan kampus ITS telah menerapkan sistem patrol rutin dengan penjadwalan tertentu. Tantangan untuk mengembangkan perangkat monitoring patroli dan sistem penjadwalan patrol yang mampu menjamin pengawasan patrol berjalan sesuai dengan perencanaan keamanan dan keselamatan kampus menjadi bahasan dalam penelitian ini dengan merancang sistem patroli SKK ITS yang lebih efektif. Peluang untuk mengembangkan aplikasi bergerak untuk monitoring patroli SKK ITS. Kompleksitas penjadwalan akan mampu di fasilitasi dengan penggunaan aplikasi bergerak dan sekaligus dapat menyusun penjadwalan tiap personil yang dinamis agar kejenuhan selama bertugas akan berkurang dengan dinamika variasi penugasan termasuk rute yang dinamis.

\section{METODE}

Pemetaan alur proses penjadwalan dan pengawasan patroli diperlukan untuk menggali tahapan proses saat ini dan sebagai acuan dalam perancangan ulang proses yang akan di otomasi menggunakan aplikasi bergerak. Studi terhadap prosedur dan rancangan jadwal patrol yang berlaku dilakukan sebagai bahan awal perancangan ulang. Fungsi-fungsi yang diperlukan dalam aplikasi bergerak dirumuskan pada tahap perancangan Antar

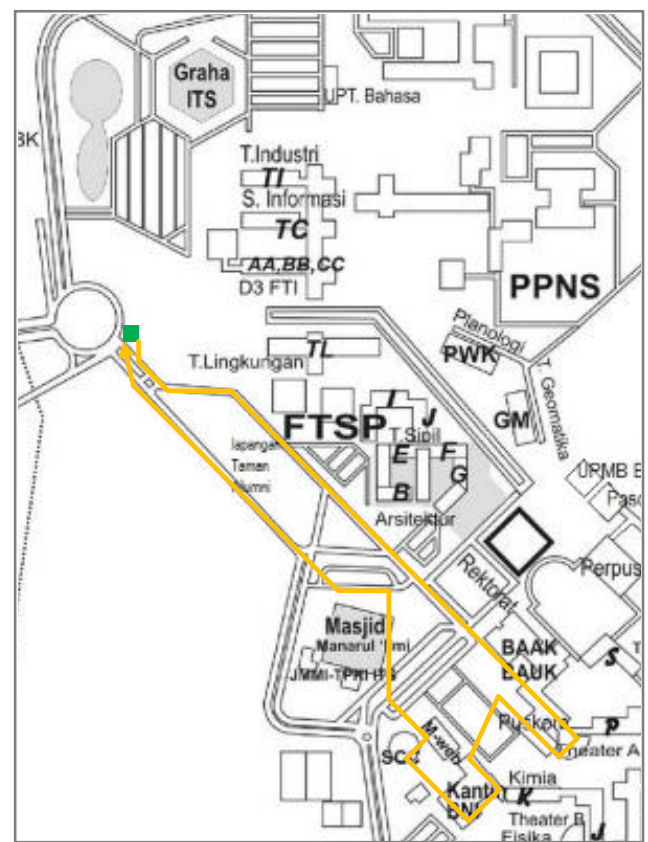

Muka atau User Interface. Antar Muka dirancang sejalan dengan perumusan fungsi aplikasi. Dengan mengacu pada racangan antar muka, setiap fungsi dari aplikasi dapat dirancang secara efektif dan mudah dipahami oleh pengembag aplikasi [3]. Antar Muka menjadi prototype awal dalam pengembangan aplikasi bergerak. Focus Group Discussion melibatkan pimpinan SKK, koordinator regu dari tiap shift SKK ITS, narasumber lainnya yang memahami tentang keamanan kampus. FGD bertujuan untuk merumuskan alur proses baku serta fungsi yang diperlukan dalam aplikasi bergerak. FGD dan wawancara juga diperlukan untuk menggali aspek-aspek penting pada tahap implementasi agar perilaku dan situasi dalam praktik patroli dapat diidentifikasi dengan lengkap dan menjadi bahan pertimbangan perancangan yang berbasis kebutuhan pengguna .

Flatform yang digunakan dalam aplikasi bergerak menggunakan Android dengan versi yang menyesuaikan dengan kebutuhan pengguna. Untuk menunjang integrase dan konektivitas antar pengguna, maka arsitektur aplikasi bergerak harus membangun server untuk menyimpan aplikasi. Arsitektur umum SIGAP ditampilkan dalam gambar 2 dibawah ini. 


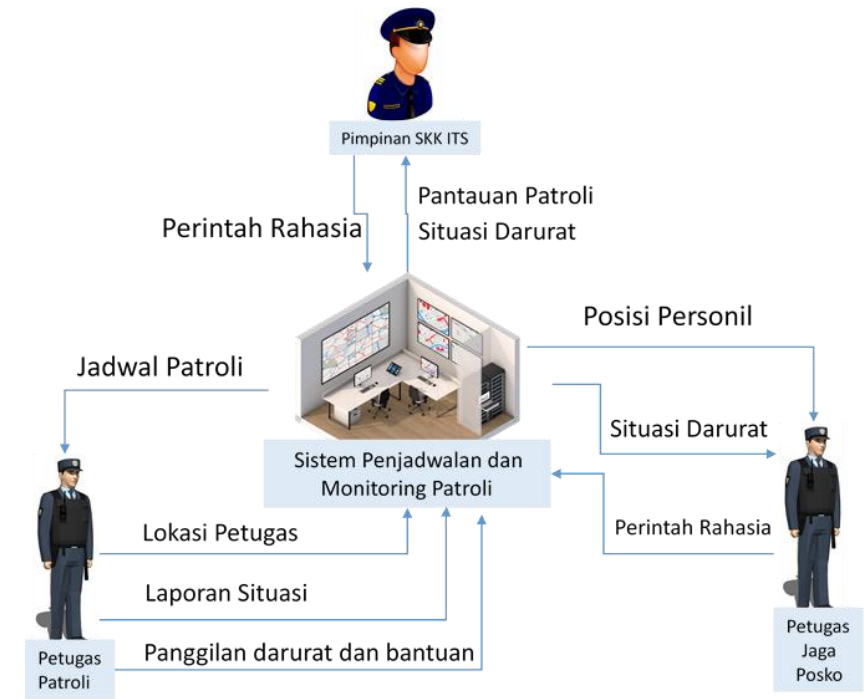

Gambar. 2 Arsitektur umum sistem penjadwalan dan pengawasan patroli kampus

Tahap usability dilakukan kepada beberapa petugas SKK di kampus ITS untuk mengetahui tingkat usabilitas aplikasi untuk mengetahui apakah kinerja aplikasi telah sesuai dengan arsitektur sistem [4].

\section{HASIL DAN PEMBAHASAN Kebutuhan Pengguna Sigap}

Analisa kebutuhan pengguna SIGAP telah dilakukan dengan melakukan wawancara kepada pengelola manajemen SKK di ITS. Dari beberapa narasumber didapatkan rangkuman kebutuhan dan fitur yang diperlukan dalam aplikasi SIGAP. Tabel 1 dibawah ini merupakan hasil identifikasi kebutuhan pengguna untuk pengembangan apliaksi SIGAP.

Tabel. 1 Fitur Aplikasi Patroli Berdasarkan Atribut

\begin{tabular}{|c|l|l|}
\hline No & \multicolumn{1}{|c|}{ Atribut } & \multicolumn{1}{c|}{ Fitur Aplikasi yang Relevan } \\
\hline 1 & $\begin{array}{l}\text { Tersedia menu panduan penggunaan pada } \\
\text { aplikasi }\end{array}$ & Panduan penggunaan aplikasi \\
\hline 2 & $\begin{array}{l}\text { Ada beberapa kalimat penjelas pada menu } \\
\text { untuk memudahkan selama penggunaan } \\
\text { aplikasi }\end{array}$ & Kalimat interaktif dalam interface aplikasi \\
\hline 3 & $\begin{array}{l}\text { Perancangan menu laporan patroli yang tidak } \\
\text { memerlukan kegiatan mengetik. }\end{array}$ & $\begin{array}{l}\text { Tombol laporan yang mewakili setiap kondisi dari } \\
\text { lokasi patroli }\end{array}$ \\
\hline 4 & $\begin{array}{l}\text { Aplikasi dapat dipasang pada smartphone } \\
\text { Android versi terdahulu dan terbaru }\end{array}$ & $\begin{array}{l}\text { Aplikasi dapat dipasang pada Android versi } \\
\text { Jellybean hingga versi Marshmallow. }\end{array}$ \\
\hline 5 & $\begin{array}{l}\text { Penggunaan kata-kata perintah yang singkat } \\
\text { dan mudah dimengerti }\end{array}$ & Kata perintah singkat dan jelas pada setiap tombol. \\
\hline 6 & $\begin{array}{l}\text { Tampilan interface yang sederhana, rapi, dan } \\
\text { menarik }\end{array}$ & $\begin{array}{l}\text { Interface aplikasi yang sederhana, rapi, menarik, } \\
\text { dan serasi. }\end{array}$ \\
\hline 7 & $\begin{array}{l}\text { Tidak ada kesalahan selama pengoperasian } \\
\text { aplikasi. }\end{array}$ & $\begin{array}{l}\bullet \text { Interface yang tidak menyesatkan pengguna } \\
\bullet \text { Notifikasi pengingat tugas. } \\
\bullet \text { Verifikasi kehadiran petugas di lokasi patroli }\end{array}$ \\
\hline 8 & $\begin{array}{l}\text { Adanya dialog konfirmasi untuk action } \\
\text { menekan tombol bahaya. }\end{array}$ & $\begin{array}{l}\text { Dialog konfirmasi saat tombol bahaya ditekan } \\
\text { untuk mencegah kepanikan yang tidak disengaja. }\end{array}$ \\
\hline
\end{tabular}

\section{Arsitektur Umum Sistem Awal}

Penerapan sistem baru akan mengubah alur proses dari suatu kegiatan, termasuk kegiatan patroli oleh SKK ITS. Dalam kegiatan patroli SKK ITS, beberapa aktivitas yang sebelumnya dilakukan secara manual akan dapat dilakukan secara otomatis oleh aplikasi. Kegiatan yang berubah teknis 
pelaksanaannya antara lain presensi kehadiran petugas, penjadwalan petugas, dan penentuan rute. Alur kegiatan patroli SKK ITS pada saat

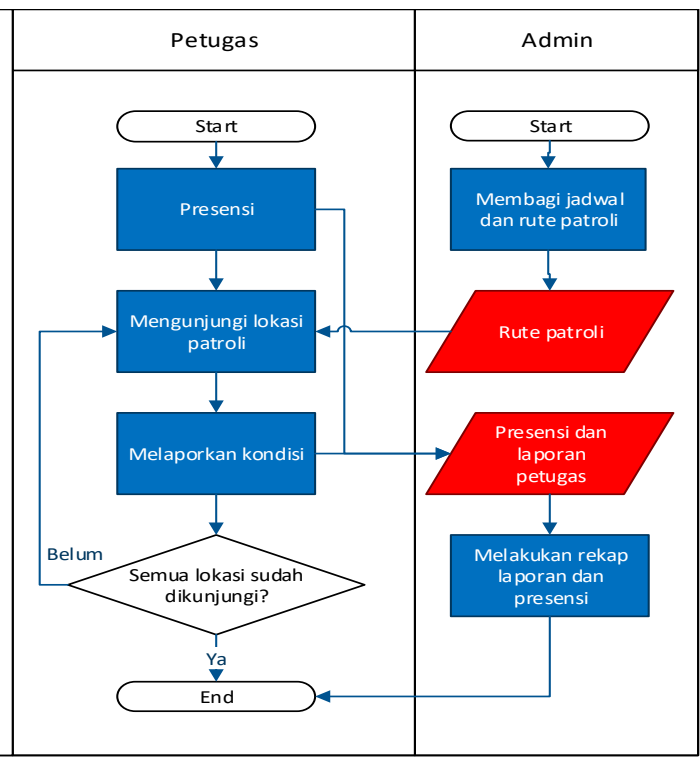

ini dan setelah penerapan aplikasi patroli ditunjukkan pada gambar 3 .

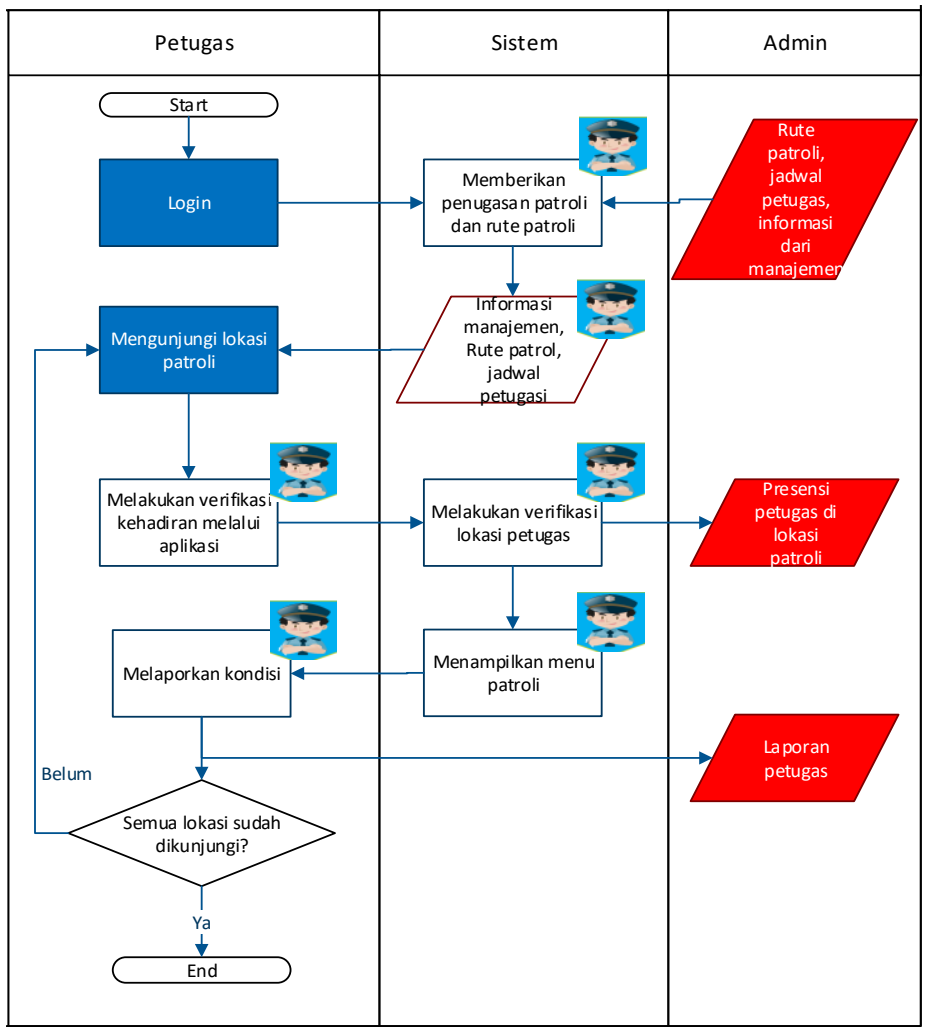

Gambar. 3 Perbandingan Proses Patroli SKK ITS Saat Ini dan Setelah Penerapan Aplikasi

Pada proses saat ini, entitas yang terlibat hanya petugas dan manajemen selaku administrator. Namun setelah penerapan aplikasi, beberapa kegiatan difasilitasi oleh sistem dalam aplikasi, yaitu pada kotak flowchart yang ditandai. Kegiatan tersebut antara lain pemberian penugasan dan jadwal patroli kepada petugas, verifikasi kehadiran di lokasi, serta pelaporan patroli. Selain itu, beberapa kegiatan yang sebelumnya dilakukan secara manual oleh admin akan dilakukan secara otomatis oleh aplikasi, yaitu pembuatan jadwal dan penugasan untuk petugas, di mana peran admin terbatas pada pembuatan database penjadwalan dan penugasan.

Penjelasan proses patroli setelah penerapan aplikasi adalah sebagai berikut. Proses patroli diawali dari kegiatan login melalui aplikasi yang menggantikan kegiatan presensi petugas. Kemudian aplikasi akan menampilkan daftar rute patroli dan jadwal petugas yang diambil dari database yang disiapkan oleh admin. Kemudian petugas melakukan patroli sesuai jadwal dan rute yang diterima. Saat petugas berada di lokasi, petugas melakukan verifikasi kehadiran melalui aplikasi untuk membuka menu patroli, yang mana kegiatan ini tidak ada sebelum penerapan aplikasi. Selanjutnya, petugas berpatroli sambil melaporkan kondisi di tempat tersebut melalui aplikasi. Laporan tersebut akan masuk ke dalam database admin. Petugas akan di-logout secara otomatis dari aplikasi setelah shift kerjanya selesai.

\section{Rancangan antar muka SIGAP}

Dalam perancangan antar muka SIGAP, aspek estitika dan usabilitas menjadi hal utama dalam menampilkan rancangan sistem yang sesuai dengan kebutuhan pengguna. Rancangan antar muka SIGAP versi kedua dapat dilihat pada tampilan gambar 4 dibawah ini. 

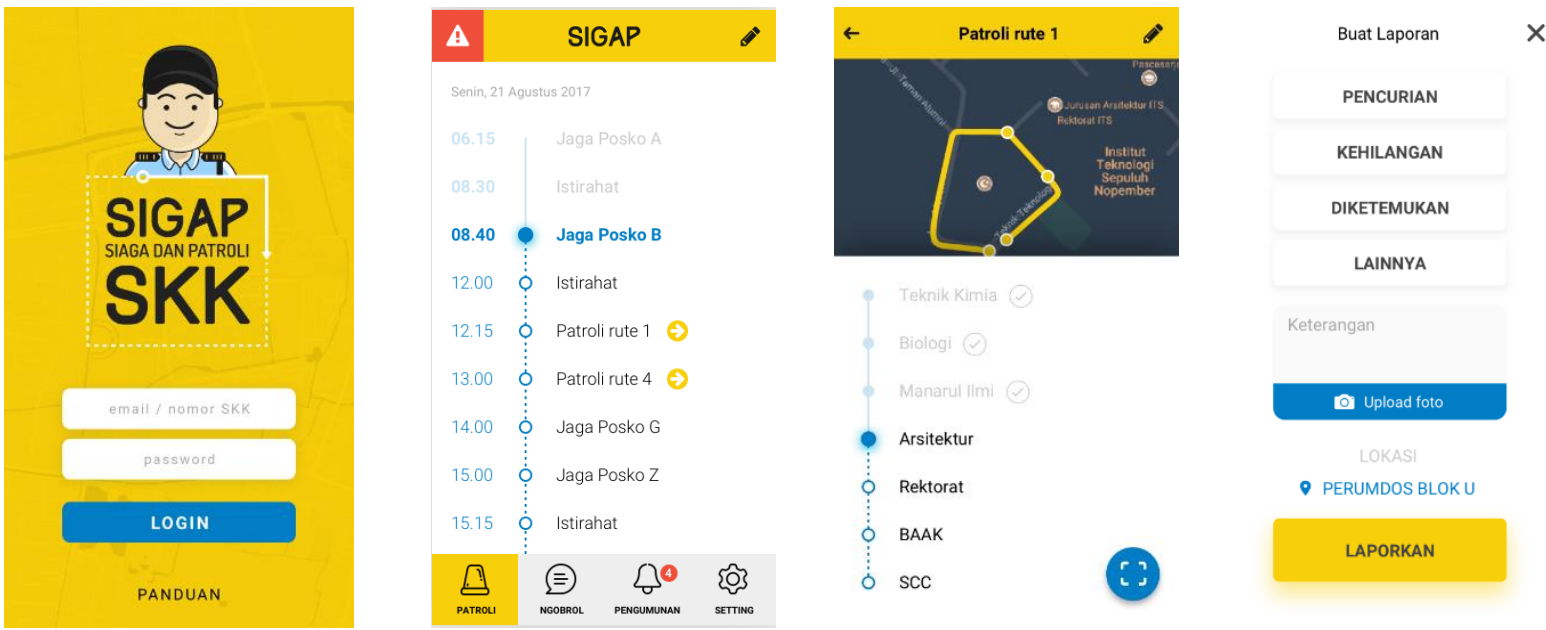

Gambar. 4 Rancangan halaman antar muka SIGAP

SIGAP dirancang agar dapat diakses dan didownload oleh semua civitas akademik ITS. Fitur tombol darurat merupakan salah satu fitur yang disiapkan bagi civitas akademik untuk mengantisipasi kondisi bahaya didalam kampus. Bila pengguna menekan tombol darurat maka sistem SIGAP akan mengirim pesan darurat ke posko utama dan seluruh petugas SKK ITS.

\section{Uji Usabilitas dan Evaluasi Sistem}

Pengujian usabilitas aplikasi SIGAP kepada pengguna penting dilakukan untuk memberikan informasi mengenai bagaimana pengguna memahami dan mengoperasikan produk dan masalah apa saja yang muncul [5]. System Usability Scale (SUS) digunakan untuk mengukur kepuasan pengguna setelah menggunakan sebuah sistem atau produk [6]. SIGAP telah diujicobakan dan didemokan kepada 13 orang responden yang merupakan anggota tim SKK dan pengelola SKK di ITS. Gambar 5 menunjukkan respon yang cenderung setuju bahwa usabilitas SIGAP sudah baik dan hampir condong pada kepuasan penggunaan aplikasi oleh para responden. Aspek no 7 yang terkait dengan konsistensi dan kehandalan fungsi SIGAP masih perlu ditingkatkan.

\footnotetext{
7. Saya pikir fungsi dalam SIGAP telah berjalan dengan konsisten termasuk tidak ada error

6. Saya merasa sangat menguasai SIGAP dengan cepat

5. Saya menemukan banyak fungsi yang sudah terintegrasi dengan baik

4. Saya rasa saya bisa mempelajari dan menggunakan SIGAP dengan cepat tanpa didampingi oleh teknisi/admin dari SIGAP

3. Saya rasa fungsi dalam SIGAP tidak ribet (komplek) untuk digunakan

2. Saya rasa SIGAP mudah untuk digunakan

1. Saya berkeinginan menggunakan SIGAP untuk meningkatkan keamanan dan keselamatan
}

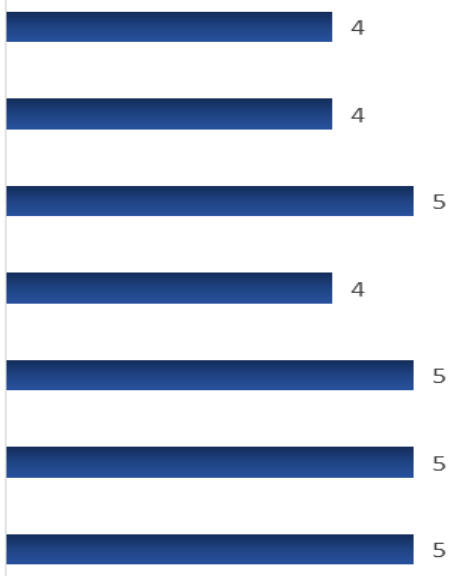

Gambar. 5 Kecondongan tingkat usabilitas SIGAP

\section{KESIMPULAN DAN SARAN \\ Kesimpulan}

Jadwal patroli petugas keamanan dan keselamatan kampus mampu diakomodir dalam aplikasi SIGAP yang akan menjadi acuan tiap user petugas dalam menjalankan tugas rutin. Penempatan QR Code pada titik lokasi kunjungan patroli perlu dilengkapi 
dengan deteksi lokasi berbasis informasi lokasi Sistem peringatan bahaya menjadi fungsi penting dalam proses pengamanan kampus. Sistem peringatan menghubungkan antara penghuni kampus dengan petugas keamanan dan keselamatan untuk mempercepat waktu respon kondisi bahaya. Fungsi pelaporan kejadian terkait kemanan dan keselamatan kampus tersedia didalam aplikasi SIGAP dan mampu memberikan kemudahan akses penyampaian kejadian dengan mudah dan cepat. Perlunya integrasi aplikasi SIGAP dengan sistem keamanan kampus yang lain termasuk dengan sistem komunikasi manual dan sistem CCTV kampus.

\section{DAFTAR PUSTAKA}

[1]. ITS International Office, 2011. Towards a World Class Research University. Surabaya, Institut Teknologi Sepuluh Nopember.

[2]. Elmadhania, A. , 2017. Optimalisasi Beban Kerja Petugas Keamanan Berdasarkan Standar Tingkat Keamanan pada

GPS.

(Studi Kasus: Satuan Keamanan dan Keselamatan ITS). Surabaya, Jurusan Teknik Industri ITS.

[3]. Bainbridge, William Sam. , 2004. Encyclopedia of Human-Computer Interaction. Great Barrington, Berkshire Publishing Group LLC.

[4]. Granic, Andrina, Mitrovic, Ivica dan Marangunic, Micola., 2011. Exploring the usability of web portals: A Croatian case study. International Journal of Information Management, page. 339349.

[5]. Nielsen, Jakob, 2012. Usability 101: Introduction to Usability. [Dikutip: 21 Maret 2016.] https://www.nngroup.com/articles/usabil ity-101-introduction-to-usability/.

[6]. Usability.gov. System Usability Scale (SUS). [Online] [Dikutip: 26 Maret 2017.] https://www.usability.gov/howto-and-tools/methods/system-usabilityscale.html. 